\begin{abstract}
Internships are now widely promoted as a valuable means of enhancing graduate employability. However, little is known about student perceptions of internships. Drawing on data from a pre-1992 university two types of graduate are identified: engagers and disengagers. The engagers valued internship opportunities while the disengagers perceived these roles as exploitative and worthless. Few were able to distinguish paid, structured internship opportunities from unpaid, exploitative roles. We conclude that HEIs need to be more proactive in extolling the value of paid internships to all students and not just those most likely to engage with their services.
\end{abstract}

Key words: Employability, internship, skills, graduate, employment, social mobility

Word Count: 7783 (including references) 


\section{Exploitation or Opportunity?: Student Perceptions of Internships in Enhancing Employability Skills}

Henrietta O'Connor and Maxine Bodicoat

\section{Introduction}

The increasing pressure on Higher Education Institutes (HEIs) to develop the employability skills of students faced with a shrinking graduate labour market and a growing pool of graduate labour is well-recognised (Brown and Hesketh, 2004; Moreau and Leathwood, 2006; Tomlinson, 2007, 2008). Similarly, the increasing emphasis on an employability discourse has created considerable pressure on individuals to develop their own employability 'relative to others within a hierarchy of job seekers' (Brown and Hesketh, 2004:25). This need for a positional edge amongst graduates in an increasingly credentialist graduate labour market means that undergraduates are highly focused on their need to first secure a 'good' degree, preferably from a highly ranked institution. What has also become clear, however, is that in order to secure the competitive edge graduate CVs need to be further enhanced to illustrate the possession of 'soft' employability skills (Moreau and Leathwood, 2006). While debates around the definition of employability continue, the message is clear, students need to ensure that they leave full-time education with a CV illustrating their employability.

This pressure has resulted in HEIs taking steps to embed the concept of employability into the curriculum and for Careers Services to provide a broad range of activities to encourage student engagement (Bridgstock, 2009; Cranmer, 2006). As part of this drive there is an increasing emphasis on extra-curricular work-related activities (ECAs), for example, volunteering, institutional award schemes and work experience placements designed to maximise the opportunity of securing a graduate level job (Tomlinson, 2008). Such opportunities have also resulted in a spectacular increase in the number and availability of graduate internships. There is widespread conviction that 'high quality' work experience placements are invaluable and 'there seems almost universal acceptance of the value of work placements and internships' (HEFCE, 2011:2). A cursory glance at any university website reveals numerous internships advertised to recent graduates or those about to graduate. Indeed, such is the perceived 
value of internships that in 2010 HEFCE provided funding to support 57 HEIs in developing internship programmes.

The position of the government has also been clear in these debates - to ensure that pathways towards greater social mobility, particularly for less advantaged individuals who are systematically excluded from high-level professional roles, are facilitated. The perceived link between the development of internships and the goal of achieving greater social mobility through widening access to the professions is promulgated as a positive government intervention, designed to 'improve the life chances of those from less advantaged backgrounds' (Brown, 2013:678). However, in framing the policy as a means of increasing social mobility 'policy debate is reduced to a deficit model of what working-class students and families lack - credentials, incentives, internships or employability skills' (Brown, 2013:682). Such a model, based on 'social change primarily driven from below, not above' (Milburn, 2009:2) does not recognise the fundamental structural constraints faced by less advantaged students in accessing opportunities such as internships. This, in turn, has created a situation whereby 'social mobility, rather than the ailments it is supposed to cure, has become the main focus of attention, a politically driven distraction that diverts our attention from the real problems that need to be addressed' (Reay, 2013: 663).

In the recent 'State of the Nation Report' (Social Mobility and Child Poverty Commission, 2014) the growth in internships is described as 'the biggest change in the professional labour market over recent years ... a new rung on the professional career ladder - yet all too often ... recruited on the basis of who, not what you know, and many are unpaid (p.xii). There is some recognition here that structural constraints act as a barrier to accessing internships. What remains, however, is an implicit emphasis on the deficit model of the working class (Loveday, 2014: 14) which intimates that the removal of the most obvious barriers to access will somehow level the playing field for all.

The key issue that this paper seeks to explore is the perception of internships amongst recent graduates at a pre-1992 institution. The paper begins with an overview of the concept of internship drawing out the differences between unpaid internships and the graduate schemes offered by many HEIs. The method of data collection and a 
profile of the sample are then outlined. The data analysis focuses on highlighting student perceptions of internships and it is argued that some students, termed here as 'Engagers' appear to understand the potential value of completing an internship in enhancing their future labour market prospects. Conversely, those classified as 'Disengagers' are shown to have more negative views of internships and rebuffed opportunities to participate in these schemes. Significantly, amongst both groups, there was evidence that the negative portrayal of internships in the media, casting internships as unpaid and exploitative had influenced perceptions and acted as a deterrent for some. This suggests that there was little understanding of the different types of internship schemes on offer and the popular focus on exploitative internships has become pervasive. The paper concludes by reflecting on the value of an internship and the impact of recent media campaigns focused on ending the practice of unpaid work experience.

\section{Internships as an Entry to Employment}

Regardless of the expansion of internship programmes the role of such opportunities in increasing employability is under-explored and little is known about internships or student perceptions of internships. Leonard (2013), for example, argues that 'our knowledge of internships is scanty and unsystematic' whilst Guile and Lahiff (2013:1) suggest that 'internship has been attracting considerable attention for a number of years and, yet, has rarely been the subject of any sustained, serious research'. Whilst academic attention may have been lacking, the proliferation of internship opportunities has attracted increasing attention from a range of sources, not least stories in the media focused on unpaid or underpaid and exploited interns putting their health at risk through long hours, exhaustion and overwork (Gallagher, 2013). The view of internships as unpaid, exploitative and highly competitive has permeated much of the popular discourse and 'the mass emergence of unpaid positions - and American style internship auctions - has stirred up serious resentment' (Perlin, 2012: 200). This has resulted in organisations such as 'Intern Aware' (http://www.internaware.org) and 'Graduate Fog' (http://graduatefog.co.uk) campaigning against exploitative and unfair internships and raising awareness of unacceptable practices by some employers. 
Most existing research on internships has focused on the significant problems associated with unpaid internships in particular professions (Allen et al., 2013; Siebert and Wilson, 2013, Sutton Trust, 2014). Unpaid internships are a widespread phenomenon in certain industries, for example, access to the professions and creative roles in journalism and media are often predicated on applicants having work experience in the industry facilitated through unpaid internships mainly based in London. Although unpaid, these roles are attractive:

'...aspiring entrants are prepared to participate in such unpaid activities because they offer them an opportunity to, on the one hand, work in contexts where they can begin to engage with the expressions of vocational practice identified (...) and, on the other hand, develop a reputation in their chosen vocational field and contacts to assist them to secure contracts for their creative services' (Guile, 2009: 775).

However, the very individuals that the government social mobility agenda is aimed at are precluded from participating in such internships as they are less likely to have resources available to support themselves for the duration of the internship. A recent Sutton Trust (2014) report illustrated how unpaid internships operate as a barrier to social mobility by excluding those without access to financial support to fund accommodation, travel and living costs. This is further compounded by employers recruiting interns by 'word of mouth' therefore those graduates with high levels of social capital are more likely to be able to secure positions than those lacking such connections (Allen et al. 2013).

An unintended consequence of the increasingly high profile given to unpaid and exploitative internships has been that other internship schemes have been increasingly vilified - a development that Guile refers to as the 'demonization' of internships. We argue in this paper that this demonization has impacted on wider perceptions of the potential value of such schemes regardless of the evidence that that structured internships can play an important role 'as a means of developing skills to benefit both individuals and employers' (Guile, 2013:1). Therefore, although 'the popular belief that all internships merely exploit young people as unpaid dogsbodies [maybe] a myth' (Guile, 2013:1) unpaid internships have become 'normalised' (Allen et al., 2013) and 
'the term internship is used by employers, graduates and the media to refer to a range of unpaid, poorly-supervised and low skills activities' (Guile and Lahiff, 2013:3).

Such portrayals of unpaid internships are powerful and have served to cloud the wider understanding of different types of scheme. Effectively, there are two types of graduate internships running in parallel with important distinctions between the two. First are the unpaid, hard to access, unregulated, highly desirable yet largely informal programmes which 'tend to go to the few who have the right connections not the many who have the talent' (Milburn, 2009:5). Second are the schemes run by HEIs which are paid, more regulated (through the link between the employer and the HEI), structured and provide training with less 'fashionable' employers usually in an SME within a local labour market. It is argued here that the inherent problems with the first type of internship have served to discredit and devalue HEI provided graduate internships thus stigmatising the concept of internships. Nevertheless, internships are increasingly vital to young people entering the labour market with evidence suggesting that more than a third of all graduate vacancies are filled by those who have already worked for the employer through work experience or internship schemes (High Fliers, 2014).

The 'demonization' of internships may be due, in part, to the recent high profile media stories of exploited interns but can also be linked to the historically low-status of vocational skills in the UK (Roberts, 1995). In the UK vocational training has always been perceived as the poor relation of academic routes, to be followed only if the young person did not have the ability to succeed at school/FE/HE. In addition, there is a classbased dimension to this argument. Vocational routes in to employment have long been favoured by working class youth, keen to focus their learning on skills that have a direct relevance to future employment. As Tomlinson (2013:98) argues:

'A marked feature of working class learners' educational identities has been the propensity to engage in forms of learning that have more immediate economic relevance while discarding those that are likely to have minimal bearing on their anticipated working lies. By contrast, the routes to 'professional' employment are largely characterised by more abstract knowledge that is rich in symbolic meaning and strongly associated with traditional 'academic' curricular ...while 
not necessarily being 'trained' they are nonetheless being groomed for types of skills and learning contexts that facilitate access to higher-level occupational pursuits'.

Thus undergraduates hold their degrees in high regard and aspire to find employment linked to their degree course. This goes some way to explaining the lack of engagement with internship opportunities amongst some graduates who view such opportunities as vocational (and therefore low-status) as opposed to the alternative academic pathways to 'graduate' jobs.

There are parallels that can be drawn here with the youth training schemes (YTS) launched by the government in response to youth unemployment in the 1980s. YTS was conceived as a 'new route in to the workforce' (Roberts, 1995) for school leavers in the same way that graduate internships are presented as a route in to a graduate job. YTS schemes, like many graduate internship programmes, were developed during a period of economic downturn 'starting out from the premise that unemployed youth 'lacked' the personal qualities that employers were looking for' (Keep and Payne, 2004:56). YTS were described as training schemes but 'it was inevitable that young people would see the scheme primarily as an alternative to unemployment and that employers would view trainees as young people who had been unable to obtain employment' (Roberts, 1995:70). There is a danger that graduate internships may well come to be viewed in a similar way by graduates and employers. Indeed, HEFCE figures reveal that amongst applicants for graduate internships over two-thirds had been either unemployed or in temporary work since graduation and prior to applying for an internship and a third of their respondents applied for a role as they had not been able to secure other long-term employment (HEFCE, 2011:79). There is the little motivation for graduates to take up an internship after graduation unless they do not have an alternative destination. This view is given by further credence by reports that suggest that graduate internship schemes have been used by some HEIs as means of manipulating institutional employability data (Chowdrey, 2014).

Another issue that served to devalue YTS was that trainees were poorly paid and few young people secured permanent employment once the government-funded training period was complete: 
'the main complaint was that the training allowance was derisory. Trainees who were firm based often complained of being exploited, especially when their training involved doing jobs for which other workers were paid wages' (Roberts, 1995: 70).

As such, YTS programmes were viewed as exploitative and as nothing more than 'warehousing' for unemployed youth. Similarly, the widely publicised unpaid nature of some internships and the lack of secure employment offered on completion of internships has led to their demonisation and poor reputation as little more than underpaid or unpaid exploitative roles.

\section{The Study}

The research on which this paper is based was carried out with recent graduates of a pre-1992 institution. Beginning in the summer of 2012 the Careers Service of this institution, in common with many other HEIs, ran a graduate internship programme offering paid, structured internship opportunities to recent graduates. The roles were defined by the HEI as paid graduate roles, with salaries matching minimum wage or higher, for periods of between 3 and 12 months. Most were with SMEs in the local region in industries including retail, marketing and sales, engineering, IT, finance and insurance, education and research, creative and cultural and science related including pharmaceuticals. Employers were paid a bursary towards salary costs and were asked to provide the graduate with work on a specific project coupled with specialised training, feedback sessions and a mentor. Employers were promised 'work-ready graduates' and the opportunity to get to know potential employees through an extended trial period. Those graduates who signed up for the scheme and who responded to this research were positive about the experience, citing the offer of permanent roles, the acquisition of skills and the enhancement of their CVs as outcomes from the experience:

Not only did I learn a lot about the world of work, but I got used to the smaller daily activities like processes and procedures companies undertake to survive. Additionally the internship is the reason why other companies began offering me interviews as they saw I had gained experience in many different areas. 
Before I took on the internship, the lack of experience from a fresh university graduate made it even more difficult to find work.

Despite intensive effort by the Careers Service only just over half $(85 / 148)$ of the vacancies were filled. Though some individuals applied and were unsuccessful in their attempt to secure an internship many graduates were unwilling to engage with the programme at all, despite being unemployed or working in non-graduate roles. This issue is not exclusive to this particular institution as the recent report on work experience and internships by HEFCE (2011:78) reveals that 'considerable effort was needed by the HEIs' to fill available internships. It is important to note here that these opportunities do not reflect the internships that are promoted by the government as opening up access to the professions. The opportunities provided by HEIs through graduate schemes tend to be located within local labour markets and not in the competitive industries where unpaid internships are commonplace. While in some sectors demand outstrips supply this tends to be in industries where there is a tradition of unpaid work experience as a means of entering a profession (Guile, 2009; Siebert and Wilson, 2013). In less fashionable sectors, and in sectors which do not traditionally rely on the internship and work experience route, there is far less of a supply issue.

In order to explore the reasons why graduates were not taking up internship opportunities an online survey was created, targeted specifically at UK-based full-time, first degree 2011/12 graduates. An online survey was created using 'Webropol' and sent to a total of 1746 graduates. At the end of the survey respondents were asked to indicate whether they would be interested in taking part in a follow-up interview. Of the 163 survey respondents, 86 individuals indicated that they would be willing to be considered for interview. The final sample consisted of twenty-three graduates (12 females/11 males).

Interviews were conducted online via Adobe Connect, using live, synchronous text-based chat so that transcripts were automatically generated. Instructions and questions were copy and pasted from a pre-prepared script to ensure consistency between interviews. Where participants digressed from pre-set topics, or made comments which warranted further investigation, the interview deviated from the script in order to address these points. 
A profile analysis was carried out on the demographics of the graduates who had participated in the 2012/13 internship programme. The sample was compared to the wider population of DLHE responders who fell into the target category of full-time, first-degree, Home students. The graduates were compared on various criteria including four key widening participation variables: POLAR3, NS-SEC, IMD and School Type. The analysis (cross tab with the application of a chi-square statistic) showed that overall there were no significant differences between the demographics of the Intern group and the wider student population, on any of the profile indicators, suggesting that overall the demographics of the Intern group were representative of the student body as whole. The data did indicate, however, that those who undertook internships as part of this scheme were, overall, high achieving students. A higher percentage (compared to the total population) entered the University with a UCAS tariff above their departmental average, and a higher percentage (compared to the total population) obtained a degree classification of 2:1 or above. These differences were not however statistically significant but, as the discussion below reveals, the trend for higher achieving students to be more engaged and more likely to explore all available opportunities also emerged from our later analyses.

\section{Perceptions of Internships amongst Recent Graduates: The Engagers and the}

\section{Disengagers}

Overall the graduates in the study had a high level of awareness of the different employability opportunities available to them but held very different views on engaging, or not, with such interventions. In broad terms the graduate perception of internships can be placed on a continuum where those with a positive view of such opportunities (the Engagers) can be placed at one extreme whilst at the other were those with a more negative outlook (the Disengagers). In between these two groups were those who were more ambivalent about internships primarily because they were either engaged in further study at the time the internship was offered, had already secured a job or were seeking a job role that they felt internships would not help them to secure.

\section{The Engagers}

The group classified here as 'engagers' consisted of individuals who had developed strategies for preparing to enter the competitive and overcrowded graduate 
labour market. As new entrants to employment these individuals recognised the need to achieve additional credentials and mirrored the graduates identified by Brown and Hesketh (2004:126) as 'players' who 'understood employability as a positional game'. The engagers understood that simply having a degree is not longer sufficient (Bathmaker et al., 2013; Tomlinson, 2008) and they sought to undertake a range of ECAs, including internships, to enhance their employability.

Even amongst this group, who had engaged with the employability agenda early on, the transition to employment was a daunting prospect and there was an awareness that the opportunities graduates are encouraged to seek out are not equally available to all. This 'opportunity trap' (Brown, 2003) impacts far more on those individuals with less advantaged backgrounds who lack access to the social, cultural and economic capitals and therefore access to high quality, valuable ECAs that are available to many of their middle-class counterparts (Bathmaker et al., 2013).

Employability interventions offered by careers services, such as internship schemes, are intended to provide opportunities for all graduates to gain work experience. An aim of such schemes is, therefore, to circumvent the barriers to social mobility that unpaid and unregulated internships have created. Hypothetically then, the provision of paid internships should act as vehicle for social mobility opening up opportunities that would not otherwise exist for students. Indeed this is the basis of recent government reports on increasing social mobility. However, this view of internships as a means of achieving social mobility depends upon opportunities being equally available to all. This predicament was articulated by Kayleigh, a working class, first generation graduate with a first class degree who came to realise that without the social and cultural capital of more advantaged graduates she was in a weak position when it came to securing relevant work experience:

I am very confident in my own abilities. But I was not confident about the job market and my chances ... In my opinion, especially now that the economy and job market is so weak, it is truly not what you know but who you know that gets you ahead. Even securing voluntary work or experience is so difficult. Nearly everyone I know who was able to do it knew someone from inside and was able to pull some strings. I feel that to an extent with my background I am at a disadvantage to many other students as my family do not have connections. 
What we see in Kayleigh's initial attitude towards higher education and her future career is a perfect encapsulation of the impact of policy aims on the individual lifecourse. Kayleigh had high aspirations, believed in her own abilities and was prepared to 'work hard' to make progress. In doing so she had believed her actions would result in returns on her personal investment. However, the structural constraints became a barrier that she had not envisaged and she quickly became aware that her lack of capital was a problem that she could not tackle through hard work alone.

What Kayleigh has experienced for herself and describes so eloquently is that no matter how intelligent an individual may be or how hard s/he works or how aspirational s/he may consider themselves to be, 'middle-class and upper-class parents heavily invest and constantly strategize to ensure that their children have a better chance of a fair chance than other people's children' (Reay, 2013: 666). Thus the opportunities offered by HEIs which meet Lehmann's (2011: 14) recommendation that 'enriching educational opportunities ... be made more accessible to individuals with few or no connections into their respective career fields...assist[ing] students with low levels of career-relevant social capital in establishing important connections' are of great importance. Amongst the engagers the value of such opportunities had been recognised and were sought after but the less advantaged graduates quickly became aware that engaging with opportunities would not result in the opening up of the same opportunities that the more advantaged graduates had at their disposal.

Nevertheless, the engagers, like Kayleigh, sought out ECAs and were enthusiastic about the role of internships in enhancing their employability. They understood the term internship in a positive way and defined such roles in much the way that that Guile and Lahiff (2013:3) have described 'best practice' internships, as a mode of learning and developing skills. The role of internships as a recruitment tool was recognised as was the need to pay interns and provide them with the same type of work as a graduate employee. In the quote below Tom demonstrates an awareness of the more controversial aspects of internships and the lack of clarity around the definition of internship:

A PAID (respondent emphasis) opportunity of at least 6 weeks (usually) within a firm, typically undertaking similar work to that which would be taken on by a 
graduate. Often a good opportunity for employers to entice prospective employees and to get a better idea than they would in an interview of how suitable the student is. I wouldn't count unpaid work experience or work experience that didn't really reflect the nature of the job as "internships".

Other graduates who viewed internships as a worthwhile endeavour had a good understanding of the purpose of an internship and focused on the experience gained by the intern of working within an organisational setting, learning about the job role, developing vocational skills and experiencing the world of work. Clearly this group perceived the merits characteristic of the best practice internships and in some cases benefitted directly from this:

It was a positive experience, I learned valuable and transferable skills that were useful to have on my $C V$ which ultimately aided me finding my current position. This experience and prior work experience all collated to make skills required for my chosen career. I think it was fantastic and doesn't need any improvement- is offers a salary and skills which are both important to recent graduates.

The engagers had, for the most part, either benefitted from their own experience of being an intern or, crucially had been very open to the idea of pursuing an internship, believing that completion of an internship would help to give them a competitive edge in a highly congested graduate labour market. Roulin and Bangerter (2011:25) describe a German study that revealed students' awareness that completing an internship would give them a competitive edge in the graduate labour market particularly if the internship were undertaken with a highly-regarded organisation. The notion of seeking out opportunities in order to stand apart from other graduates was significant for many of this group, as Harry articulates in his definition of the concept:

A career stage after graduation that provides valuable experience and training that will provide people with an advantage over other graduates when looking for full-time, permanent employment.

Similarly, Louise explained her view that an internship can help graduates to develop skills that other job seekers will lack: 
Slave labour? No. An opportunity to work within an organisation, supervised in realistic tasks in order to gain practical, transferable, tangible experience. Very useful in distinguishing yourself from other graduates.

Phil, a geography graduate who went on to complete and internship and secure a permanent position with the same employer, explained that as an undergraduate he had been very focussed on his future pathway. Although he recognised the value of having a 'good degree' from a highly ranked institution he also recognised that academic qualifications are no longer sufficient as a means of appealing to future employers:

I was involved in a number of societies and held committee positions in one of the largest sports clubs. I also had a part-time job working at the University. I felt that getting a good degree from a top University ... combined with work experience, a part time job and a commitment to a number of sports clubs would appeal to a number of employers.

He went on to explain how the internship had met his expectations in enhancing his CV and securing his current job:

It was very positive, it provided me with essential experience and boosted my $C V$ significantly. As a result, I was able to gain employment in a sector in which I believe I would have been otherwise unsuccessful. It provided me with valuable experience in the industry that I did not previously have, as well as almost all of the competencies in the person specification for the new role I have just acquired.

To some extent the individuals quoted above can be viewed as traditional 'life planners' (Brooks and Everett, 2008) who aspire and plan to follow linear transitions from education to employment. They had made an active decision to pursue a particular pathway at university in order to maximise their future success in a challenging graduate labour market. Significantly these individuals 'were able to articulate specific reasons for behaving in the way (such as the need to take a more proactive stance in the 
labour market...)' (Brooks and Everett, 2008: 329). For some of the respondents this planning took them only as far as the completion of their undergraduate degree. For others, the life planning went much further and, as we have seen in the preceding quotes, these young people pursued an active strategy to enrich their CVs in order to maximise their potential in the labour market once graduated.

Thus far the emphasis in this paper has been on those graduates who recognized the potential benefit of completing an internship. They also shared an outlook that emphasised the importance of personal investment in employability and understood the 'need to add value to their credentials in the light of their weakening value' (Tomlinson, 2008:59). One of the strengths of this piece of research, however, is that we also have data from 'disengagers'; those graduates who although approached by the institution and offered the opportunity to apply for an internship decided not to pursue the option. This has enabled us to gain some insight in to the reasons why some graduates do not engage in this type of programme.

\section{The Disengagers}

The disengagers were characterised by their lack of uptake of internship opportunities, a decision underpinned, primarily, by their negative perceptions or misunderstanding of the concept of internships. There was a widespread belief that internships would be unpaid and exploitative and a lack of understanding of the term 'internship' which was often confused with apprenticeship amongst this group. Farida, a psychology graduate who didn't apply for an internship, expressed this quite succinctly:

I think that there can be an emphasis on the benefits of applying for an Internship as some students might be unaware of what they entail and potentially miss out on valuable opportunities.

Farida went on to explain that she had not applied for an internship as she 'didn't feel I had the time to juggle an application, potential job and my University work'. This attitude is very much at odds with the behaviour of the engagers, many of whom took on multiple tasks whilst still undergraduates in order to meet what they viewed as the 
forthcoming challenges of the graduate labour market. There was evidence here that like the students in Bathmaker et als. (2013:736) study, some disengagers were playing by 'the 'old' rules of the game' and were focused on achieving a good degree. For example, Nick who explained his attitude to university as being focused on achieving a first rather than planning his future beyond graduation:

'I was determined to gain a lst class degree. Although I had very few aspirations for after university, I aspired to doing my best whilst there'.

Amongst other disengagers an adverse view of internships was much more apparent. Nathan's quote, below, suggests that negative conceptions have taken on more prominence over time. He draws a distinction between the historical meaning of internships as a means of transitioning in to employment and the current view of internships as exploitative:

The original concept: A company willingly takes on a student in order to help them develop their abilities and shape their future career path with the benefit of first-hand experience.

The modern concept: Free/below minimum wage work from desperate students. Hope you know how to make good coffee champ.

In a later interview Nathan expanded on his view of internships and demonstrated a good understanding of the limitations of unpaid internships, highlighting the role of media in informing his view:

Let me explain my reasoning here: my view of this is informed by the media and experiences of friends \& acquaintances, I decided that I'd refuse to do any unpaid work - though as a Computer Science grad, I'm lucky enough to have a skillset which is currently in demand. However, in more competitive (and crowded!) fields, such as fashion, politics and the media, these days, it's completely common and expected that the bottom of the pyramid doesn't start with entry-level jobs, instead, with internships. 
Other respondents held similar negative views and these had played a role in their decision not to pursue this type of work experience. As Jack, a chemistry graduate explained:

Anecdotally, I think the very phrase "internships" can have negative connotations to students. Students like to feel their degree has gained them skills which others do not have. Internship seems to imply a sense of being a "newbie".

Jack also had a clear idea that his future career path should be linked to his degree subject and he felt that an internship would not offer this type of opportunity:

'[I] had specifically wanted to gain a place on a graduate scheme, or go on to further PhD study. I wanted to have a job relevant to my degree discipline and the internships on offer didn't seem to help with that'.

The idea that to be worthwhile any future work opportunities or internships should be closely related to the degree subject study held significant currency amongst this group:

I wanted to get a job in a technical discipline. This was not helped using the internships on offer as I was worried that accepting an unsuitable position could damage my chances later. They are also highly competitive and I knew there were better candidates than me so it was not in my interest to devote time applying to these.

Without any doubt the primary negative view of internships was around the issue of such roles being unpaid or very poorly paid. When asked to define an internship the graduates frequently mentioned lack of pay as a deterrent. The engagers tended to be more accepting of the low paid nature of some internships and saw the benefits as outweighing the limitations:

A usually unpaid chance to experience what it is like to work in a company with an aim to giving you a foot in the door if you apply for a job with that company. 
However, amongst the disengagers more emotive language such as 'slavery' or 'slave labour' and 'exploitation' was used when describing internships. Pete, a law graduate from a disadvantaged background, was very dismissive of internships although he had not had direct experience of them, describing the roles as:

'slavery in disguise/ work experiencel professional hot drinks maker. This is a question that I cannot give a sufficient answer for because I did not concern myself with looking for internships during my degree and I only go on what I hear from friends and their experiences'

There was also a view that internships were of benefit only to the employer and 'a waste of time' for graduates as Robert, a chemistry graduate described: Tea and biscuit delivery coordinator. i.e. a massive waste of time. The view that interns were unlikely to receive a high quality training experience and were more likely to be used as 'dogsbodies' had significant currency. Paid work experience gained through part-time employment was perceived as being more authentic and worthwhile than experience gained as an intern. This view was predicated on the perception that interns do little more than watch other people work:

Students should be made considerably more aware of recruitment agencies who will take graduates onto their books very easily ... The jobs might not be exactly what you want but you'll have more responsibility than an unpaid 'internship' which is little more than wandering around looking over people's shoulder.

Internships and extra-curricular activities were not on my mind because I felt they would not be as useful to me as I wanted them to. Plus, I had a part-time job so if potential employers were looking for work experience then I felt that actually working rather watching people work seemed like the better option.

This lack of distinction between different types of workplace and employment exposure is fascinating. In some ways it is not a surprising viewpoint particularly for lessadvantaged and often non-traditional students for whom paid work is becoming a necessity (Moreau and Leathwood, 2007). Nevertheless, it is more surprising that this view of work experience continues post-graduation. There is evidence here that internships have such negative connotations for some graduates that they cannot 
envisage that the potential benefits of these schemes may outweigh the short-term financial returns of temporary work secured through employment agencies. Those graduates who would benefit most from such access to potential future employers and career paths are seemingly not aware of the evidence that employers are increasingly recruiting graduates through participation in internship schemes (High Fliers, 2014).

\section{Conclusion}

The current climate of the massification of higher education, a simultaneous shrinkage of the graduate labour market and an increasing neo-liberal emphasis on students to improve their own employability makes the transition to employment a complex one. On the one hand various agencies are promoting the idea of internships to graduates as a vehicle for social mobility and a pathway for widening access to the professions, as a way of enhancing employability, learning new skills in a workplace setting. Careers Services in HEIs are increasingly offering access to internships for both undergraduates during their studies and graduates once they have completed their degrees. HEFCE are also keen to promote internship opportunities to graduates. However, on the other hand, current students and recent graduates are also being bombarded with media stories focused on the scourge of unpaid internships, social media campaigns aimed at ending unpaid internships and so on. Whilst the aim of such campaigns is both admirable and necessary this emphasis may well be skewing the wider perception of internships, leading to misunderstandings of the range of internships available and serving to compound the existing problem of access to internships.

As this paper has shown, those most likely to research internships and to apply for such roles are those students who are already engaged with improving their own employability and those who, it can be argued, are least in need of such experiences. Without doubt the influence of social class, gender and ethnicity are also at play here and cannot be ignored. Engagement in ECAs has been shown elsewhere to be strongly mediated by social factors such as class status and middle-class students, for example, are more likely to participate in such activities during their studies (Lehmann, 2011). Although like Bathmaker et al. (2013) we found that the vast majority of students were aware of the increasing value of ECAs to their employability, access to relevant and valued opportunities remains blocked for those without relevant capital. 
The less engaged students appear to accept without questioning the 'demonised' image of internships (Guile and Lahiff, 2013) and avoid applying for these roles even when such roles are paid, structured and may lead to full-time graduate positions. As Allen et al. (2013:442) have argued of students in the creative industries 'the normalisation of unpaid placements led working-class students to self-select how many and what kinds of placements they undertook on the basis of their financial situation'. In reality the situation is similar for all students but the difference now is that many students are self-selecting not to pursue an internship believing such roles to be exploitative, unpaid and valueless. This is regardless of the evidence that much graduate recruitment now takes place through internship schemes many of which are paid and structured.

There is then something of a paradox at work here in that the most desirable and potentially valuable opportunities remain concentrated in the hard to access, unregulated and unpaid sectors. This serves to ensure that less advantaged students remain 'blocked' from competing for such roles on many levels and are then more likely to dismiss alternative schemes. As Leonard (2013) has argued, 'internships may have become a key mechanism for middle class kids to get middle class jobs, potentially also reproducing divisions of ethnicity, gender and place'. This was certainly a concern for our respondents, one of whom commented that:

I'm not sure how much the university can do to help on this front, but it's certainly a real Catch-22 for students and graduates, as most will not have parents that can support them if they choose to do internships and pursue a career in these fields; and I do really think that society will be a lot poorer for it, if only the independently wealthy end up qualified/experienced enough to work in politics and the media.

However, what this paper has also shown is that this discourse has led some students to dismiss the potential value of a paid, structured and regulated internship believing that all schemes are largely unpaid and exploitative or open only to the most well-connected and privileged graduates. 
Without a certain level of engagement from the graduates at whom such programmes are aimed, it is unlikely that all places will be filled and less privileged students will continue to miss out on opportunities to secure employment in graduate level roles. Internships alone will not produce a 'social mobility dividend' (Milburn, 2009: 1) but may provide access to a congested labour market and therefore smooth the transition from education to work for many. It is imperative, therefore, that HEIs offering internship programmes work hard to ensure that such opportunities are not only open and accessible to all students but that the potential value of such opportunities are equally understood across the entire student population. 


\section{References}

Allen, K., Quinn, J., Hollingworth, S. and Rose, A. (2012) Becoming employable students and 'ideal' creative workers: exclusion and inequality in higher education work placements. British Journal of Sociology of Education 34 (3) 431-452.

Bathmaker, A.M., Ingram, N. and Waller, R. (2013) Higher education, social class and the mobilisation of capitals: recognising and playing the game. British Journal of Sociology of Education 34 (5-6) 723-743.

Bridgstock, R. (2009) The graduate attributes we've overlooked: enhancing graduate employability through career management skills. Higher Education Research and Development, 28 (1) 31-44.

Brooks, R. and Everett, G. (2008) The prevalence of 'life planning': evidence from UK graduates. British Journal of Sociology of Education, 29 (3), 325-337.

Brown, P. (2003) The Opportunity Trap: Education and Employment in a Global Economy. European Educational Research Journal 2: 141-177.

Brown, P. (2013) Education, opportunity and the prospects for social mobility. British Journal of Sociology of Education, 34 (5-6), 678-700.

Brown, P. and Hesketh, A. (2004) The Mismanagement of Talent: Employability and Jobs in the Knowledge Economy. Oxford: Oxford University Press.

Chowdrey, N. (2014) Are Universities fudging employment figures? The Huffington Post, 29/8/14. http://www.huffingtonpost.co.uk/nick-chowdrey/universitiesemployment-figures_b_5721570.html accessed October 20th 2014.

Cranmer, S. (2006) Enhancing graduate employability: best intentions and mixed outcomes. Studies in Higher Education, 31 (2), 169-184. 
Gallagher, P. (2013) Slavery in the City: Death of 21-year-old intern Moritz Erhardt at Merrill Lynch sparks furore over long hours and macho culture at banks, The Independent, 20/8/13, http://www.independent.co.uk/news/uk/home-news/slavery-inthe-city-death-of-21yearold-intern-moritz-erhardt-at-merrill-lynch-sparks-furoreover-long-hours-and-macho-culture-at-banks-8775917.html accessed December 12th 2013.

Guile, D. (2009) Conceptualizing the transition from education to work as vocational practice: lessons from the UK's creative and cultural sector. British Educational Research Journal, 35 (5) 761-779.

Guile, D. (2013) Industry Interns: Glorified Gofers or Valued Learners? LLAKES press release, July $5^{\text {th }} 2013$. http://www.llakes.org/2013/07/industry-interns-glorifiedgofers-or-valued-learners/ accessed January $28^{\text {th }} 2014$.

Guile, D. and Lahiff, A. (2013) Internship: Conventional Wisdom, Models and Recommendations. CET and Institute of Education, University of London.

HEFCE (2011) Increasing Opportunities for High Quality Higher EducationWork Experience. Career Development Organisation (CRAC) Oakleigh Consulting Limited. http://nases.org.uk/files/he\%20work\%20exp\%20hefce\%20report11.pdf accessed December $8^{\text {th }} 2013$.

High Fliers (2014) The Graduate Market in 2014, http://www.highfliers.co.uk/download/GMReport14.pdf accessed November 22nd 2014.

Keep, E. and Payne, J. (2004) "I can't believe it's not skill”: the changing meaning of skill in the UK context and some implications', in G. Hayward and S. James (eds.), Balancing the Skills Equation - Key issues and challenges for policy and practice, Bristol: Policy Press, 53-76. 
Lehmann, W. (2011) Extra-credential experiences and social closure: working-class students at university. British Educational Research Journal, iFirst article, 1-16.

Leonard, P. (2013) 'The Internship': Precarious Work Futures \#2 http://blog.soton.ac.uk/wfrc/blog/2013/07/the-internship-precarious-work-futures-2/ accessed September $24^{\text {th }} 2013$.

Loveday, V. (2014) Working-class participation, middle-class aspiration? Value, upward mobility and symbolic indebtedness in higher education. The Sociological Review, DOI: 10.111/1467-954X.12167

Mellors-Bourne, R. and Day (2011) Evalutaion of the Graduate Talent Pool Internship Scheme. BIS Research Paper Series, No. 8.

http://www.bis.gov.uk/assets/biscore/higher-education/docs/e/11-668-evaluation-ofgraduate-talent-pool-internships.pdf accessed December $12^{\text {th }} 2013$.

Milburn, A. (2009) Panel on Fair Access to the Professions: Unleashing Aspiration. The final report of the panel on fair access to the Professions. London: Cabinet Office

Moreau, M.P. and Leathwood, C. (2006) Graduates' employment and the discourse of employability: a critical analysis. Journal of Education and Work 19 (4) 305-324.

Moreau, M.P. and Leathwood, C. (2007) Balancing Paid Work and Studies: Working (-Class) Students in Higher Education, Studies in Higher Education, 31 (1), 23-42.

Perlin, R. (2012) Intern Nation: How to Earn Nothing and Learn Little in the Brave New Economy. London and New York:VersoBooks

Reay, D. (2013) Social mobility, a panacea for austere times: tales of emperors, frogs, and tadpoles. British Journal of Sociology of Education 34 (5-6) 660-677.

Roberts, K. (1995) Youth and Employment in Modern Britain. Oxford: Oxford University Press. 
Roulin, N. and Bangerter, A. (2011) Students' Use of Extra-Curricular Activities for Positional Advantage in Competitive Job Markets. Journal of Education and Work, $26(1), 21-47$.

Siebert, S. and Wilson, F. (2013) All work and no pay: consequences of unpaid work in the creative industries. Work, Employment and Society, 27 (4) 711-721.

Social Mobility and Child Poverty Commission (2014) State of the Nation 2014:

Social Mobility and Child Poverty, available at:

https://www.gov.uk/government/uploads/system/uploads/attachment_data/file/365765 /State_of_Nation_2014_Main_Report.pdf accessed November $12^{\text {th }} 2014$.

Sutton Trust (2014) Internship or Indenture. Research Briefing, November 2014, accessed 13/11/14: http://www.suttontrust.com/wp-content/uploads/2014/11/UnpaidInternships.pdf

Tomlinson, M. (2008) The degree is not enough: students' perceptions of the role of higher education credentials for graduate work and employability. British Journal of the Sociology of Education, 29 (1) 49-61.

Tomlinson, M. (2013) Education, Work and Identity: Themes and Perspectives. London: Bloomsbury. 